Review Article

\title{
Exploring the Pivotal Immunomodulatory and Anti- Inflammatory Potentials of Glycyrrhizic and Glycyrrhetinic Acids
}

\author{
Seidu A. Richard 10 \\ Department of Medicine, Princefield University, P. O. Box MA 128, Ho, Ghana \\ Correspondence should be addressed to Seidu A. Richard; gbepoo@gmail.com
}

Received 5 November 2020; Revised 9 December 2020; Accepted 19 December 2020; Published 7 January 2021

Academic Editor: Rômulo Dias Novaes

Copyright (C) 2021 Seidu A. Richard. This is an open access article distributed under the Creative Commons Attribution License, which permits unrestricted use, distribution, and reproduction in any medium, provided the original work is properly cited.

\begin{abstract}
Licorice extract is a Chinese herbal medication most often used as a demulcent or elixir. The extract usually consists of many components but the key ingredients are glycyrrhizic (GL) and glycyrrhetinic acid (GA). GL and GA function as potent antioxidants, anti-inflammatory, antiviral, antitumor agents, and immuneregulators. GL and GA have potent activities against hepatitis $\mathrm{A}, \mathrm{B}$, and $\mathrm{C}$ viruses, human immunodeficiency virus type 1, vesicular stomatitis virus, herpes simplex virus, influenza A, severe acute respiratory syndrome-related coronavirus, respiratory syncytial virus, vaccinia virus, and arboviruses. Also, GA was observed to be of therapeutic valve in human enterovirus 71, which was recognized as the utmost regular virus responsible for hand, foot, and mouth disease. The anti-inflammatory mechanism of GL and GA is realized via cytokines like interferon- $\gamma$, tumor necrotizing factor- $\alpha$, interleukin- (IL-) $1 \beta$, IL-4, IL-5, IL-6, IL-8, IL-10, IL-12, and IL-17. They also modulate antiinflammatory mechanisms like intercellular cell adhesion molecule 1 and P-selectin, enzymes like inducible nitric oxide synthase (iNOS), and transcription factors such as nuclear factor-kappa B, signal transducer and activator of transcription- (STAT-) 3, and STAT-6. Furthermore, DCs treated with GL were capable of influencing T-cell differentiation toward Th1 subset. Moreover, GA is capable of blocking prostaglandin-E2 synthesis via blockade of cyclooxygenase- (COX-) 2 resulting in concurrent augmentation nitric oxide production through the enhancement of iNOS2 mRNA secretion in Leishmania-infected macrophages. GA is capable of inhibiting toll-like receptors as well as high-mobility group box 1 .
\end{abstract}

\section{Introduction}

Licorice extract is a Chinese herbal medication most often used as a demulcent or elixir [1]. Glycyrrhizin (GL) is one of the principally effective and efficient ingredients of licorice extract [1-3]. GL is a triterpene saponin which has aglycone component known as glycyrrhetinic acid (GA) [1]. GA is a pentacyclic triterpenoid of oleanene type with a hydroxyl group at C-3, a carboxyl moiety at C-30 as well as a ketone functional group at C-11 [2]. GL and GA have been demonstrated to possess antioxidant properties as well as robust anti-inflammatory, antiviral, antitumor, and immuneregulatory properties [4-6]. GL was capable of triggering the blockade of receptor-mediated endocytosis resulting in the inhibition of viral infiltration into the cells $[5,7]$.

GL triggers biological activities at the cellular level via novel gbPs, which are responsible for anti-inflammatory and antiviral effects $[5,8]$. GL was capable of triggering the production of interferons (IFNs), accelerated the activities of natural killer (NK) cells as well as regulated the growth response of lymphocytes via the acceleration of interleukins(IL-) 2 production $[1,8,9]$. Furthermore, GL has the ability to modulate the immune response at the initial stage of the disease process via the dendritic cells (DCs) [10]. GA inhibited anti-FAS antibody-triggered mouse liver injury but did not facilitate the upregulation of tumor necrotizing factor- $\alpha$ (TNF- $\alpha$ ) messenger RNA (mRNA) secretion in the liver [11].

This review explores the fundamental immune and inflammatory players regulated by GL and GA. The "boolean logic" was utilized to search for the article on the subject matter. Most of the articles were indexed in PubMed with strict inclusion criteria being in vitro and in vivo up or downregulation of these immune and inflammatory biomarkers in diverse disease conditions. Inflammation, DCs, cyclooxygenase, and prostaglandins, cytokines like ILs, IFNs, TNF- $\alpha$, nuclear factor- $\kappa \mathrm{B}(\mathrm{NF}-\kappa \mathrm{B})$, mitogen-activated protein kinase 
(MAPK), Toll-like receptors (TLRs), high-mobility group box 1 (HMGB1), and chemokines like CCL11 as known as eotaxin 1 as well as enzymes like nitric oxide were explored.

\section{Uses}

Glycyrrhizin (GL) obtained from the dried roots of the licorice shrub is very sweet tasting and has been utilized as flavors in diverse food products and treatment of diseases for over 4000 years [12]. Currently, GL is used to flavor consumable products like chocolate, chewing gum, some alcoholic beverages, and cigarettes $[12,13]$. Carbenoxolone (GC), the derivative of glycyrrhetinic acid ( $3 \beta$-11-oxoolean-12-en-30oic acid 3-hemisuccinate), was used to treat peptic ulcer disease, allergic diseases, tumors or cancers, divers' viral diseases, and premenstrual syndromes [4-6]. They possess antiinflammatory, antioxidant, antihyperglycemic, antilipidemic, and hepatoprotective properties [4-6]. Their key therapeutic usage of GC is for the treatment of viral diseases [14]. Chronic hepatitis $\mathrm{C}$ is the current target for use of GC in modern medicine $[12,15]$.

Several in vivo and in vitro studies showed that GL and GA have potent activities against hepatitis A, B, and C viruses, human immunodeficiency virus (HIV) type 1, vesicular stomatitis virus, herpes simplex virus, influenza A, severe acute respiratory syndrome- (SARS-) related coronavirus, respiratory syncytial virus, vaccinia virus, and arboviruses [2, 7, 16-20]. Also, GA was observed to be of therapeutic valve in human enterovirus 71 , which was recognized as the utmost regular virus responsible for the hand, foot, and mouth diseases [2]. GL and GA demonstrated to have antibacterial actions against gram-positive bacteria like Bacillus subtilis and Staphylococcus aureus as well as gramnegative bacteria like Escherichia coli and Pseudomonas aeruginosa [2, 21, 22]. Furthermore, GA was capable of blocking the survival of methicillin-resistant S. aureus via the attenuation of its virulence gene expression $[2,23]$. Also, GA has demonstrated to have antiparasitic potentials and its efficacy as an anti-malarial as well as antileishmanial has been elaborated in experimental studies [2, 24, 25].

\section{Pharmacokinetics}

GA is rapidly absorbed after oral administration, and its kinetics exhibited a biphasic association with a distribution phase preceded by a slower elimination phase $[12,26]$. The medication is usually in a capsule form containing $500 \mathrm{mg}$ of pure GA per capsule [26]. It was established that neither absorption nor elimination of GA was dose-dependent [26]. Several studies detected GA in both rats as well as human plasma [12]. On the other hand, GL is metabolized presystemically via commercial bacteria into GA and totally absorbed into the blood stream after oral intake $[12,27]$.

Studies have shown that the hydrolysis of GL to GA was carried out by bacteria strains like Eubacterium sp. (strain GHL), Ruminococcus sp. (PO1-3), and Clostridium innocuum (ES2406). These commercial bacteria were isolated from human feces and demonstrated enough hydrolyzing activity for GL $[12,28,29]$. The bacteria strains capable of hydrolyzing GL into GA possess a specific $\beta$-glucuronidase, because common $\beta$-glucuronidases like Escherichia coli were unable to hydrolyze GL $[12,28]$. After hydrolysis of GL into GA, intestinal bacteria convert GA partially into 3- $\alpha$-18 $\beta$-GA, through a metabolic intermediary 3-oxo-18 $\beta$ GA $[12,27]$.

Also, the plasma clearance of GL after an intravenous bolus dose to rats exhibited a biphasic pattern, in which the distribution phase was preceded by a slower elimination phase $[30,31]$. However, realistic plasma levels of GA were observed to be approximately $100 \mathrm{mg} / \mathrm{ml}$ after intravenous administration $[30,31]$. Also, the distribution of GA to the body tissues was negligible because tissue-to-blood partition coefficients were observed to $<1$ for all body tissues of rats $[12,32]$. Interestingly, the uptake of GL into rat hepatocytes was competitively blocked by GA (46). This means that the plasma to liver transport of GA is facilitated by the same uptake carrier [31].

Studies have demonstrated that habitual usage of GA in consumable products may lead to adverse effects [12, 33]. It was established that capacity-regulated activities facilitate the metabolism, sinusoidal, and canalicular transport of GL [12]. Furthermore, GL was hydrolyzed by glucuronidases into 18- $\beta$-GA monoglucuronide in lysozymes of both rodents and humans [12]. This process may ultimately lead to edema, hypertension, and symptoms associated with electrolyte imbalances $[12,34]$.

\section{Inflammation}

The fundamental processes involved in the eradication of threats posed to the host to organisms like bacterial and viral infections are the triggering of an acute inflammatory response [35]. Studies have shown that GL was capable of binding directly to lipoxygenase resulting in the generation of inflammatory mediators [36-38]. Also, GL selectively blocked the triggering of phosphorylation of these inflammatory mediators, which are mainly enzymes [36-38]. Specifically, GL as well as its derivatives was capable of blocking the generation of inflammatory chemokines like IL-8 and eotaxin 1, which are both powerful chemo-attractants to leukocytes during inflammation (Figure 1) [36, 39]. GL as well as its derivatives was also capable of neutralizing the secretion of these proinflammatory chemokines $[36,39]$.

On the other hand, GA was capable of decreasing the secretion of vascular endothelial growth factor (VEGF), intercellular cell adhesion molecule 1 (ICAM-1), granulocytemacrophage colony-stimulating factor (GM-CSF), and human growth-regulated oncogene/keratinocyte chemoattractant (GRO/KC) in alcoholic hepatitis rats' models (Figure 1 and Table 1) [40]. GA was also capable of inhibiting phospholipase A2/arachidonic acid (PLA2/ARA) (Table 1) pathway metabolites, like prostaglandin-E 2 (PGE2) or prostacyclin 2, thromboxane $2\left(\mathrm{TXA}_{2}\right)$, and leukotriene B4 (LTB4) (Figure 1) [41, 42]. It was stipulated that the antiinflammatory response to GL and GA was a result of direct binding the molecules to cell membrane constituents like lipocortin I (LC-1) or to enzymes such as PLA2 (Table 1), which is the prime enzyme in the arachidonic acid metabolic 


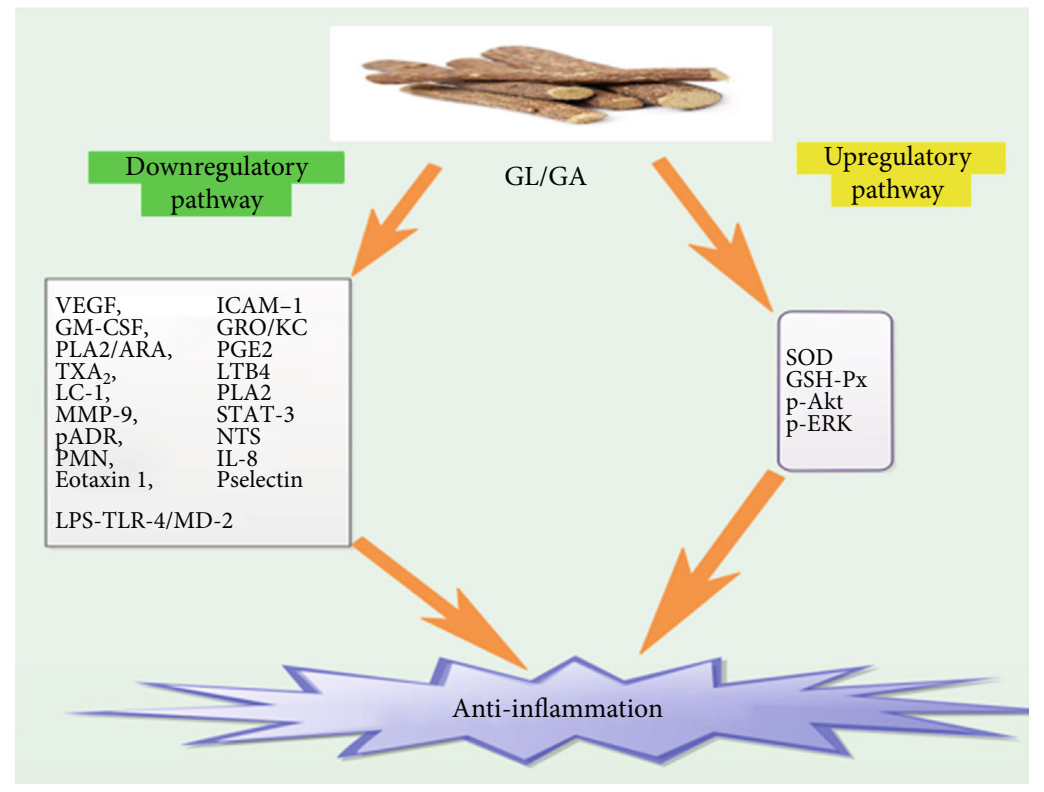

FIgURE 1: Shows a comprehensive down and upregulatory pathways via which GL and GA elicits anti-inflammation.

pathway (Figure 1) [36]. GA ominously decreased the concentration of ICAM-1 as well as matrix metalloproteinase-9 (MMP-9) (Figure 1) [41, 43]. Furthermore, it augmented the actions of Superoxide dismutase (SOD) and glutathione peroxidase (GSH-Px), as well as the secretion of $\mathrm{p}$-Akt and p-ERK (Figure 1) [41, 44].

GL and GA efficiently blocked the generation of free radicals in LPS-treated Raw264.7 macrophage models [41]. They also decreased the configuration of the LPS-TLR-4/MD-2 complexes, leading to the blockade of homodimerization of TLR-4 (Figure 1) [45, 46]. Thus, GA was able to regulate the TLR-4/MD-2 complex at the receptor level, resulting in the inhibition of LPS-induced triggering of signaling cascades as well as cytokine generation [45]. This signifies that GA blocked inflammatory responses as well as regulated innate immune responses $[45,47]$.

Furthermore, GA inhibited the stimulation of signal transducers and activators of transcription-3 (STAT-3), decreased the upregulation of ICAM-1 as well as Pselectin secretion, decreased the configuration of polyadenosine diphosphate-ribose (pADR) and nitrotyrosine (NTS), and decreased polymorphonuclear neutrophil infiltration (PMN) (Figure 1 and Table 1) [45-47]. Moreover, GA elicited broad anti-inflammatory actions via its interaction with the lipid bilayer resulting in the decrease of receptor-mediated signaling $[45,46]$. GA was capable of blocking the lytic pathway of the complement system as well as averted tissue injury triggered by membrane attack complexes [45].

\section{Dendritic Cells}

Dendritic cells (DCs) are a group of bone-marrow-derived cells found in blood, tissues, and lymphoid organs [48-50]. These cells initiate and control immune responses that are affected by numerous factors like origin, phenotype, and maturation status [48-50]. Their prime function is to bridge the innate as well as adaptive immune systems [48-50]. DCs were able to accelerate allogeneic $\mathrm{T}$-cell proliferation in vitro [4]. A study revealed that only a minute quantity of DCs was enough to trigger an allogeneic mixed lymphocyte reaction (MLR) $[4,48]$. Studies have demonstrated that DCs are the most crucial antigen-presenting cells (APCs) associated with the uptake, processing, transport, and presentation of antigens to $\mathrm{CD}^{+}$and $\mathrm{CD} 8^{+}$T-cells $[4,49,51]$.

Also, DC subsets are capable of triggering or inhibiting immune responses via the secretion of different costimulatory molecules and cytokines $[4,52]$. DCs were able to trigger as well as target naive $\mathrm{T}$-cells to differentiate into $\mathrm{T}$-helper (Th)1 or T-helper (Th) 2 cells $[4,53]$. Thus, DCs have potential immunomodulatory therapeutic targets for some pharmacological compounds [4, 10]. Bordbar et al. demonstrated that DCs treated with GL were capable of influencing T-cell differentiation toward Th1 subset (Figure 2) (Table 1) [4]. Abe et al. also observed the upregulation of IL-10 expression by liver DCs [54]. Hua et al. established that GL was capable of augmenting IL-10 production in DC2.4 cell line (Figure 2) [55]. A current study demonstrated that GL was capable of augmenting IL-10 production along with IFN- $\gamma$ in MLR [4]. On the other hand, Bhattacharjee et al. exhibited that GA was capable of blocking the expression of the Th2, IL-10, and TGF- $\beta$ from the splenocytes of infected mice (Figure 2) [25].

\section{Nuclear Factor- $\boldsymbol{\kappa} B$}

The nuclear factor- $\kappa \mathrm{B}(\mathrm{NF}-\kappa \mathrm{B})$ family is made up of five groups such as NF- $\kappa \mathrm{B} 1$, which comprise of p50/p105 with p50 as the precursor, NF- $\kappa$ B2 which comprise of p52/p100 with p52 as the precursor, Rel A with p65 as the precursor, Rel B with p68 as the precursor, and c-Rel with p75 as the precursor $[56,57]$. Almost all the groupings are capable of 
TABLE 1: Shows the explicit effect of GL or GA on various immune/inflammatory factors.

\begin{tabular}{|c|c|c|c|}
\hline Immune/inflammatory factors & Type & Effect of GL/GA & Citations \\
\hline \multirow[t]{14}{*}{ Inflammation } & VEGF & Inhibitory & {$[40]$} \\
\hline & ICAM-1 & Inhibitory & {$[40]$} \\
\hline & GM-CSF & Inhibitory & {$[40]$} \\
\hline & $\mathrm{GRO} / \mathrm{KC}$ & Inhibitory & {$[40]$} \\
\hline & PLA2/ARA & Inhibitory & {$[36,41,42]$} \\
\hline & MMP-9 & Inhibitory & {$[41,43]$} \\
\hline & STAT-3 & Inhibitory & [45-47] \\
\hline & STAT-6 & Inhibitory & [45-47] \\
\hline & pADR & Inhibitory & [45-47] \\
\hline & NTS & Inhibitory & [45-47] \\
\hline & PMN & Inhibitory & [45-47] \\
\hline & SOD & Facilitatory & {$[41,44]$} \\
\hline & GSH-Px & Facilitatory & {$[41,44]$} \\
\hline & TGF- $\beta$ & Facilitatory & {$[25]$} \\
\hline \multirow[t]{3}{*}{ Dendritic cells (DCs) } & T-cell & Facilitatory & {$[4]$} \\
\hline & Th1 & Facilitatory & {$[4]$} \\
\hline & Th2 & Facilitatory & {$[25]$} \\
\hline \multirow[t]{2}{*}{ Nuclear factor- $\kappa \mathrm{B}$} & - & Inhibitory & {$[6,20,62-65]$} \\
\hline & IKK & Inhibitory & {$[56]$} \\
\hline \multirow[t]{3}{*}{ Chemokines } & CXCL10 & Inhibitory & {$[20,30,70,71]$} \\
\hline & CCL5 & Inhibitory & {$[20,30,70,71]$} \\
\hline & CCL11 & Inhibitory & {$[39,76-78]$} \\
\hline Interferons & IFN- $\gamma$ & Facilitatory & [85-89] \\
\hline \multirow[t]{2}{*}{ Cyclooxygenase } & COX-1 & - & - \\
\hline & COX-2 & Inhibitory & {$[25,65,98]$} \\
\hline \multirow[t]{10}{*}{ Interleukins } & IL-1 & Inhibitory & {$[8,104-106]$} \\
\hline & IL-2 & Facilitatory & {$[4,9,106]$} \\
\hline & IL-3 & Inhibitory & {$[8,104-106]$} \\
\hline & IL-4 & Inhibitory & {$[8,104-106]$} \\
\hline & IL-5 & Inhibitory & {$[8,104-106]$} \\
\hline & IL-6 & Inhibitory & {$[8,104-106]$} \\
\hline & IL-10 & Inhibitory & {$[8,104-106]$} \\
\hline & IL-12 & Inhibitory & {$[4,8,104-106]$} \\
\hline & IL-13 & Inhibitory & {$[8,104-106]$} \\
\hline & IL-18 & Inhibitory & {$[8,104-106,111]$} \\
\hline \multirow[t]{4}{*}{$\begin{array}{l}\text { Mitogen-activated } \\
\text { protein kinase }\end{array}$} & - & Inhibitory & {$[6,115,116,141]$} \\
\hline & p38MAPK & Inhibitory & {$[6,115,116]$} \\
\hline & ERK & Inhibitory & {$[45]$} \\
\hline & JNK & Inhibitory & \\
\hline \multirow[t]{3}{*}{ Nitric oxide } & iNOS & Inhibitory & {$[45]$} \\
\hline & eNOS & - & - \\
\hline & nNOS & - & - \\
\hline \multirow[t]{5}{*}{ Toll-like receptors } & TLR-3 & Inhibitory & [131-134] \\
\hline & TLR-4 & Inhibitory & {$[131-134,141]$} \\
\hline & TLR-7 & Inhibitory & {$[131-134]$} \\
\hline & TLR-9 & Inhibitory & [131-134] \\
\hline & TLR-10 & Inhibitory & {$[131-134]$} \\
\hline High-mobility group box 1 & - & Inhibitory & {$[141,142]$} \\
\hline
\end{tabular}




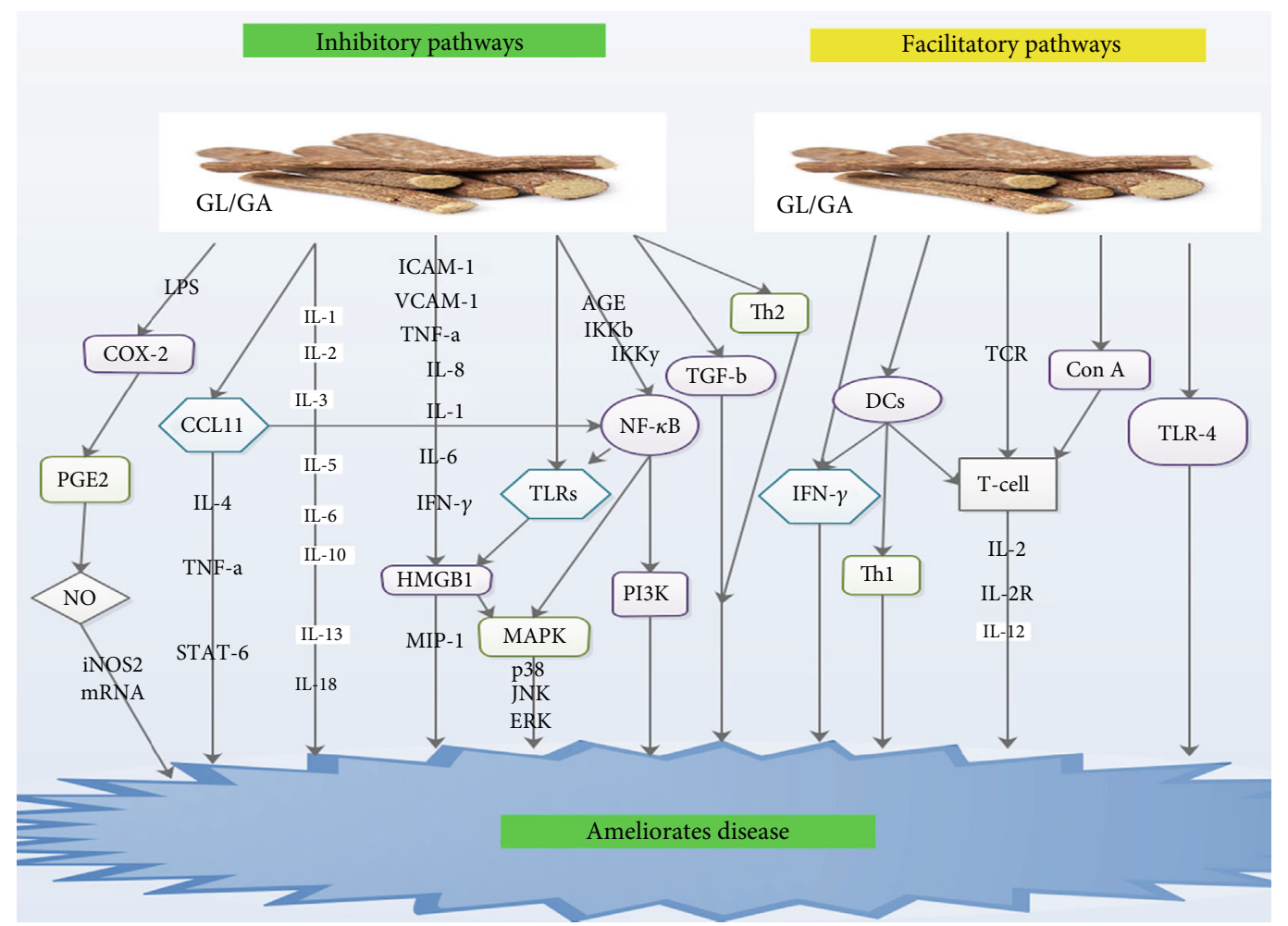

FIGURE 2: Shows the inhibitory and facilitatory pathways via which GL and GA ameliorate disease.

preserving homodimeric as well as heterodimeric complexes [56]. Nevertheless, the most predominant-stimulated form of NF- $\kappa \mathrm{B}$ is the heterodimer $\mathrm{p} 50-\mathrm{p} 65$, which has the transactivity territory obligatory for gene modification [58-60]. In most cells, NF- $\kappa$ B exists as a latent, inactive, $\mathrm{I} \kappa \mathrm{B}$ bound complex in the cytoplasm [56]. Nevertheless, upon stimulation by extracellular stimuli, NF- $\kappa \mathrm{B}$ promptly translocates to the nucleus and triggers gene release $[56,61]$.

$\mathrm{I} \kappa \mathrm{B}$ kinase (IKK) is a large multisubunit protein kinase active via numerous signal pathways [56]. The IKK complex when triggered results in the phosphorylation or degradation of $\mathrm{I} \kappa \mathrm{B} \alpha$ leading to the expression of NF- $\kappa \mathrm{B}$ [56]. NF- $\kappa \mathrm{B}$ then translocates to the nucleus and triggers the transcription of numerous $\kappa \mathrm{B}$-dependent genes, such as iNOS as well as Th1 cytokines [56]. Thus, some pathogens are capable of blocking the action of NF- $\kappa \mathrm{B}$ via the inhibition of the degradation of I $\kappa B$ during infection [56]. Also, in macrophages, the MAPK cascade and the NF- $\kappa$ B pathway are the key pathways via which modulation of inflammation as well as host defense occurs [56].

Ukil et al. demonstrated that the kinase properties of IKK were triggered in cells that were stimulated with GA via a mechanism that most probably involves upregulatory signaling pathways [56]. They however did not observe any influence of GA on IKK activity when GA was added directly to the assay mixture containing IKK immunoprecipitated from normal macrophages (Table 1) [56]. An earlier study revealed that GA influenced the inhibitory interaction between NF- $\kappa \mathrm{B}$, which is a fundamental modifier to IKK $\beta$ and IKK $\gamma$ (Figure 2) [62]. Another study indicated that GA inhibited one of the essential upregulatory kinases like
NF- $\kappa$ B-inducing kinase, PI3K, or MAPK in the signaling pathway (Figure 2) [63].

GL was capable of treating coxsackievirus B3- (CVB3-) triggered myocarditis via the blockade of CVB3-triggered NF- $\kappa \mathrm{B}$ activity via the inhibition of NF- $\kappa \mathrm{B}$ inhibitor $\mathrm{I} \kappa \mathrm{B}$ (Table 1) [20,64]. Wang and Du revealed that pretreatment with GL substantially inhibited the facilitation of NF- $\kappa$ B p 65 protein secretion, in methotrexate-stimulated enteritis (Table 1) [6]. Cherng et al. showed that GL blocked NF- $\kappa B$ secretion, averted DNA damage, and accelerated DNA repair (Table 1) [65]. Feng et al. demonstrated that GA safeguards advanced glycation end-product- (AGE-) stimulated endothelial dysfunction via blockade of the receptor for AGE/NF- $\kappa$ B signaling pathway (Figure 2 and Table 1) [66].

\section{Chemokines}

Chemokines are a family of molecules associated with the trafficking of leukocytes in normal immune surveillance and recruitment of inflammatory cells in host defense [67-69]. They are made up of over 40 groups, which are classified into four classes founded on the sites of essential cysteine residues like C, CC, CXC, and CX3C [67]. GL was capable of subduing the H5N1-triggered generation of CXCL10, and CCL5 resulting in the blockade of H5N1-triggered apoptosis [20,70]. Michaelis et al. demonstrated that $100 \mathrm{mg} / \mathrm{ml}$ of GA drastically blocked secretion of CXCL10, and CCL5 at the mRNA and the protein levels (Table 1) [30]. Augmented CXCL10 levels were observed in patients with $\mathrm{H} 5 \mathrm{~N} 1$, and the elevated levels of CXCL10 were associated with poor prognosis (Table 1) [30, 71]. 
CCL11 known as eotaxin 1 was primarily detected as the prime eosinophil chemoattractant in the lung lavage fluid after allergic exposure in guinea pigs [39]. Subsequently, it was cloned for further studies [39, 72, 73]. Several studies have demonstrated that numerous types of cells, such as lung or dermal fibroblasts, as well as lung or bronchial epithelial cells are capable of producing eotaxin $1[39,74,75]$. Studies further revealed that the production of eotaxin 1 was triggered by IL- 4 and inhibited by IFN- $\gamma[39,74,75]$. It was also observed that eotaxin 1 facilitated the infiltration of eosinophils into allergic inflammatory sites $[39,74,75]$.

Matsui et al. indicated that GL may be capable of modulating chemokine generation via the posttranscriptional level such as protein expression or mortification [39]. They demonstrated that GL derivatives had inhibitory effects on eotaxin 1 generation via TNF- $\alpha$ as well as IL- 4 induction in lung fibroblasts (Figure 2) [39]. Studies have shown that induction of IL-4 and TNF- $\alpha$ in combination synergistically accelerated the generation of eotaxin 1 via the triggering of transcriptional factors like STAT- 6 and NF- $\kappa \mathrm{B}$ (Figure 2) [76-78]. GL and its derivatives thus blocked eotaxin 1 production at protein or mRNA secretary levels (Table 1) $[39,76]$.

\section{Interferons}

Interferons (IFNs) are a family of broad-spectrum antiviral glycoproteins expressed by cells upon attack by viruses. They are often involved in numerous immune responses as triggers, modulators, and effectors of both innate as well as adaptive immune systems during viral infections [79, 80]. They have the ability of blocking viral replication and are often the most prominent cytokines produced during viral infections $[79,80]$. IFN- $\gamma$, which is expressed by lymphocytes, has been implicated in the secretion of histocompatibility antigen as well as immune modifications $[6,81]$. Studies have demonstrated that IFN- $\gamma$ was capable of facilitating the endotoxin-stimulated generation of $\mathrm{NO}$ in murine macrophages $[79,80]$.

Studies have shown that IFN with or without adenine arabinoside was capable of curing hepatitis B patients [1, $82,83]$. IFNs were capable of reducing the level of either DNA polymerase or hepatitis $B$ surface antigen in hepatitis patients $[1,84]$. Furthermore, GL was capable of facilitating IFN- $\gamma$ production in human T-lymphocytes $[85,86]$. Also, GL was capable of inducing the production of IFN in mice, which was preceded by stimulation of macrophages as well as the increase of $\mathrm{NK}$ activity $[87,88]$. Bhattacharjee et al. demonstrated that splenic expression of IFN- $\gamma$, TNF- $\alpha$, and IL-12 elevated after GA treatment. Wu et al. also demonstrated that GL drastically decreased inflammatory via IFN$\gamma$ (Figure 2) [89]. They concluded that blockade of the IFN$\gamma$ signaling pathway may be linked to anti-inflammatory effects of GL in enteritis [89].

\section{Cyclooxygenase and Prostaglandins}

COX-1 and COX-2 are the main cyclooxygenase (COX) isoenzymes, which catalyze the formation of prostaglandins, thromboxane, and levuloglandins [90]. Prostaglandins are autocoid facilitators that influence practically all recognized physiological as well as pathological activities via their reversible communication with G-protein attached membrane receptors [90]. Amongst the COX isoenzymes, COX2 was more inducible with low secretory levels in most tissues under normal circumstances $[6,91]$. It was established that numerous cell types such as vascular smooth muscle cells, endothelial cells, mononuclear macrophages, and fibroblasts were capable of secreting COX-2 up to about 8-10-fold the normal level when stimulated by proinflammatory cytokines $[6,92]$.

It was further observed that augmentation of COX-2 levels resulted in the generation as well as buildup of prostaglandin inflammatory factors, facilitating inflammatory responses as well as tissue damage $[6,91]$. Studies have shown that oversecretion of COX-2 facilitated cell proliferation, blocked apoptosis, and blocked immune responses, resulting in abnormal modulation of the balance between proliferation and apoptosis $[6,91,92]$. Bhattacharjee et al. demonstrated that a robust antileishmanial protection was observed via the modulation of macrophage-secreted COX2-determined PGE2 levels [25]. Also, Leishmania organisms were capable of using immune modulators like TGF- $\beta$, IL4 , and arachidonic acid metabolites to inhibit macrophage functions and facilitated the organism's survival within the host [93].

PGE2 biosynthesis comprises two successive enzymatic reactions [25]. The first one is a rate-limiting step involving the COX enzyme, while the second is a precise PGE synthesis step [25]. In pathophysiological processes, the inducible isoform of COX-2 was capable of modulating PGE2 production while COX-1 was principally copied $[25,94,95]$. Studies have shown that augmented level PGE2 was capable of modulating several immune responses via mechanisms involving the blockade of Th1 cytokines like IL-2, IL-12, and IFN- $\gamma$, as well as inhibition of phagocytosis and lymphocyte proliferation $[25,96,97]$. Thus, PGE2 ability to modulated immune response is champion by Th1- or Th2-associated lymphokines $[25,96]$.

It was established that GA was capable of blocking PGE2 synthesis via blockade of COX-2 resulting in concurrent augmentation NO production through enhancement of iNOS2 mRNA secretion in Leishmania-infected macrophages (Figure 2 and (Table 1) [25]. Wang and Du demonstrated that pretreatment with GL significantly blocked the facilitation of COX-2 activity in methotrexate-triggered enteritis [6]. Cherng et al. also demonstrated that GL was able to block COX-2 secretion, inhibited DNA damage, and promoted DNA repair (Table 1) [65]. Ni et al. observed an upsurge in COX-2 secretion in lung tissues after introducing LPS in their experiment, which was subsequently decreased in a dosedependent manner after GL pretreatment (Figure 2 and Table 1) [98].

\section{Interleukins}

Interleukin belongs to a group of cytokines, which are perhaps the most essential messenger molecules generated 
by leukocytes to modulate the biological activities of target cells via autocrine or paracrine means [99]. Several groupings of ILs have been identified [99]. Notable amongst them are IL-1, IL-2, IL-3, IL-5, IL-6, IL-10, IL-12, IL-13, and so many others $[3,8,99-101]$. Although most of the ILs are influenced by GL and GA, IL-12 is the most influential. IL-12 is a heterodimeric cytokine produced primarily by macrophages and monocytes [8]. Its key function is the modulation of cytokines as well as T-cell subsets [8]. A study revealed that a deficiency in endogenous IL-12 production influenced the progression of immunodeficiency in HIV-infected patients $[8,102]$. Studies have proven that IL-12 salvaged numerous activities of cells infected with $\operatorname{HIV}[8,103]$.

Several studies have demonstrated that IL-12 was capable of influencing T-cells and natural NK cells resulting in cell proliferation, cytolytic activities, and triggering of IFN- $\gamma[8$, 104]. Studies further revealed that the polarization of the $\mathrm{T}$ helper response to a Th1-dominant form via IL-12 was accelerated by IFN- $\gamma$ resulting in the blockade of IL- 4 production $[8,100,101]$. GA was capable of blocking IL-1 $\beta$, IL-3, IL-5, IL-6, IL-10, IL-12 subtypes, IL-13 (Figure 2), eotaxin, and TNF- $\alpha$ expression (Table 1) $[8,104-106]$. GL was also capable of accelerating the proliferation of lymphocytes and acted as a facilitator of the late signal transduction of $\mathrm{T}$ lymphocytes for IL-2 generation (Table 1) $[4,106]$.

Zhang et al. also indicated that GL facilitated TCRmediated T-cell proliferation by selectively influencing the late signal transduction for IL-2 generation as well as IL-2R secretion [9]. They further indicated that GL exhibited two separate activities on immature thymocytes resulting in the facilitation of IL-2 generation on one hand and blocked growth response on the other $[9,107]$. A hepatitis study revealed that IL- 4 was capable of stimulating STAT6, which in turn stimulated eotaxin secretion as well as triggered IL5 secretion [40, 108]. Wang and Du established that GA was capable of relieving methotrexate-stimulated upsurge of TNF- $\alpha$, IL- $1 \beta$, and IL- 6 levels, as well as elevated IL- 10 levels, in rats with enteritis (Table 1) [6]. GL was able to facilitate the IL-10 production by hepatic dendritic cells in mice with hepatitis (Table 1) [76].

Studies have proven that IL-10 is a well-known antiinflammatory cytokine $[40,109,110]$. It was capable of modulating STAT3 in hepatocytes as well as macrophages/Kupffer cells $[40,109,110]$. A study revealed that GA was capable of accelerating LPS-triggered IL-12 generation by peritoneal macrophages (Table 1 ) $[4,8]$. Its optimal effect on IL-12 gene secretion was linked to an upsurge in NF- $\kappa \mathrm{B}$ modulation [4, 8]. Dai et al. demonstrated that GL accelerated both IL-12 mRNA buildup as well as protein expression by peritoneal macrophages in response to LPS [8]. They indicated that the priming influence of GL on IL-12 generation did not depend on IFN- $\gamma$ or GM-CSF [8]. Thus, they also affirmed that the facilitation of IL-12 p40 mRNA secretion by GL may be via the modulation of NF- $\kappa \mathrm{B}$ [8].

Yoshida et al. demonstrated that GL was able to block the upsurge in serum levels of IL-18 in LPS/D-galactosamineinduced liver injury (Figure 2 and Table 1) [111]. Thus, GL blocked the generation of IL-18 in this model [111]. They also observed fewer IL-18-positive infiltrating cells after the introduction of GL [111]. Also, GL was capable of blocking the infiltration of neutrophils and macrophages in liver injury [111]. Furthermore, GL-stimulated decrease in immunoreactive IL-18 was probably due to blockade of cell infiltration in the liver [111]. GL was able to inhibit an upsurge in alanine aminotransferase activity when exogenous IL-18 was administered in mice treated with LPS/D-galactosamine [111]. Thus, GL blocked IL-18-mediated inflammatory response in the pathogenesis of liver injury [111]. Nakanishi et al. demonstrated that IL-18 was capable of triggering gene secretion as well as the synthesis of TNF- $\alpha$, IL-1, FAS ligand, and many chemokines [112].

\section{Mitogen-Activated Protein Kinase}

Mitogen-activated protein kinase (MAPK) signal transduction pathways are linked with cell proliferation, differentiation, apoptosis, and angiogenesis [6]. Specifically, the p38 mitogen-activated protein kinase (p38MAPK) signal transduction pathway modulates stress responses, like inflammation as well as apoptosis $[6,113]$. Studies have shown that LPS as well as other factors is capable of triggering the MAPK pathways resulting in the secretion of many inflammatory mediators via complex signal conduction pathways, which facilitates inflammation [6]. Furthermore, the modulation of p38MAPK was observed in various transduction pathways, which in turn stimulated many transcription factors as well as mediated a variety of biological activities $[6,114]$.

Wang and Du demonstrated that pretreatment with GA remarkably inhibited the facilitation of p38MAPK in methotrexate-stimulated enteritis (Table 1) [6]. They concluded that the anti-inflammatory actions of GA were probably linked to p38MAPK signaling (Figure 2) [6]. Also, studies have shown that GA lessens glycative stress in the kidneys of diabetic mice via the blockade of p-p38MAPK $[115,116]$. It was further established that GA was capable of blocking the modulation of JNK, p38 protein, and ERK (Figure 2 and Table 1) in bone marrow-derived macrophages (BMMs) [45].

\section{Nitric Oxide}

Nitric oxide (NO) is a radical messenger molecule generated by the enzyme nitric oxide synthase (NOS) [117-119]. So far, only three isoforms of NOS have been identified. Amongst the three, only two of them, NOS in neurons (nNOS) and in the endothelial cells of blood vessels (eNOS), are intensely secreted [117-120]. These two are capable of producing only minute quantities of $\mathrm{NO}$, which is sufficient to trigger cellular signaling in stress conditions.

Studies have shown that NO in an inflammatory mediator is capable of modulating innate immunity as well as pathophysiology of many infectious diseases [117, 121, 122]. The third kind of NOS is the inducible nitric oxide synthase (iNOS) $[117,119]$.

Studies have further proven that iNOS generates NO in hepatocytes as well as macrophages $[117,119,121,122]$. The stimulation of iNOS is modulated via a posttranscriptional mechanism that is mediated by antisense transcripts 
(asRNAs) $[117,122]$. Several studies have shown that the asRNAs are transcribed from the iNOS gene and interact with iNOS mRNA to stabilize the same iNOS mRNA [122, 123]. Studies have demonstrated that the iNOS is triggered by cytokines like IFN- $\gamma$ and TNF- $\alpha$, which in turn produce large quantities of $\mathrm{NO}[117,119,121,123]$. It is well proven that NO generated by iNOS was capable of triggering an inflammatory liver damage $[117,124]$.

Studies have demonstrated that concanavalin A (Con A) was capable of triggering the stimulating the T-cells in mice and induced the secretion of proinflammatory cytokines associated with the progression of hepatitis (Figure 2) [119, 125]. Furthermore, GL was capable of inhibiting Con Astimulated mouse liver damage without influencing the generation of IFN- $\gamma$ and TNF- $\alpha[119,126]$. Tsuruoka et al. demonstrated that GL blockade of liver damage was via the inhibition of iNOS mRNA as well as its protein secretion (Table 1) [119]. Thus, GL inhibited iNOS mRNA and protein in Con A-stimulated hepatitis [119]. Also, GL was capable of blocking the secretion of iNOS mRNA stimulated by carbon tetrachloride in hepatic tissue (Table 1) $[119,127]$.

\section{Toll-Like Receptors}

Toll-like receptors (TLRs) are sensors for pathogen-associated molecular patterns (PAMPs) [128]. TLRs are capable of modulating several immune responses, especially during the infectious process [128]. Several studies have shown that the secretion of TLR-3, TLR-4, TLR-7, TLR-9, and TLR-10 genes from hepatic tissue was upregulated in some viral infection models $[129,130]$, and GA or GL is capable of inhibiting these receptors (Table 1) [131-134]. It was established that the TLR4 pathway comprises of two dissimilar signaling pathways such as the myeloid differentiating primary response gene 88- (MyD88-) dependent as well as the MyD88-independent pathway $[135,136]$. It was further revealed that stimulation of the MyD88-dependent pathway led to the generation of proinflammatory cytokines via triggering of $\mathrm{NF}-\kappa \mathrm{B}$, while the stimulation MyD88-independent pathway led to the generation of type 1 IFNs $[135,136]$.

A study revealed that TLR-4 was the fundamental receptor of the innate immune signaling responses to influenza virus as well as other respiratory viruses [137]. Several studies have shown that the TLR-4 was more associated with respiratory syncytial virus and human papillomavirus infections $[129,138,139]$. Shi et al. revealed that TLR-4 gene deficiency was not associated with the downregulation of virus titer in the liver during MHV-A59 infection [129]. They observed that in MHV-A59 infection, the HMGB1-TLR-4 axis utilizes proinflammatory activities without directly influencing virus replication [129].

A study demonstrated that GA was not capable of influencing TLR-4 gene secretion during viral infection [129]. Nevertheless, the secretion of the TLR-4 gene facilitated MHV-stimulated hepatic inflammation injury as well as determined HMGB1 secretory levels in the serum (Figure 2) [129]. Several studies have proven that pretreatment with a TLR-4 inhibition agent reduced the HMGB1 levels from virus-infected cells via the TLR4-NF- $\kappa$ B path- way (Figure 2) $[129,139,140]$. Studies further revealed that the inactivation of $\mathrm{NF}-\kappa \mathrm{B}$ led to a reduced expression of different proinflammatory cytokines like IL-1 $\beta$, IL-6, TNF$\alpha$, and HMGB1 (Figure 2) [129, 139, 140]. GL was capable of blocking porcine epidemic diarrhea virus infection, as well as reduced proinflammatory cytokine expression via the HMGB1/TLR4-p38MAPK pathway (Figure 2 and Table 1) [141].

\section{High-Mobility Group Box 1}

High-mobility group box 1 (HMGB1) protein is a nuclear protein that functions as an architectural chromatinbinding factor $[142,143]$. HMGB1 is the prime signal during tissue damage usually involving necrotic and apoptotic cells [142]. Furthermore, HMGB1 performs dual functions in the nucleus and the cytoplasm [142]. Also, extracellular HMGB1 facilitates both local as well as systemic responses in the organism [142]. These responses often include inflammation, modulation of innate as well as adaptive immunity $[142,143]$. Several studies have demonstrated that HMGB1 is secreted by monocytes, macrophages, neutrophils, platelets, and dendritic and NK cells [142, 144].

Several studies have shown that HMGB1 induces macrophages, monocytes, and neutrophils to secrete proinflammatory cytokines like TNF- $\alpha$, IL-1, IL-6, IL- 8 , and MIP-1 via p38- and JNK MAPK-dependent pathways (Figure 2) [145, 146]. It was established that HMGB1 was passively secreted by damage alveolar endothelial cells or macrophages during virus-mediated cytolysis [145]. Once expressed, extracellular HMGB1 was capable of mediating injurious pulmonary inflammatory response like neutrophil infiltration, derangement of epithelial barrier, lung edema, and lung injury [145, 147]. These injurious pulmonary inflammatory responses subsequently result in respiratory failure as well as death [147].

Also, human microvascular endothelial cells are capable of secreting ICAM-1, vascular adhesion molecule-1 (VCAM-1), proinflammatory cytokines like TNF $\alpha$, IL-8, and chemokines in response to HMGB1 activation (Figure 2) [145, 148]. This means that HMGB1 was capable of disseminating inflammatory response in the endothelium during infection or injury [145]. Chemotactic as well as mitogenic actions of HMGB1 depends on its association with the receptor of advanced glycation end products (RAGE) [142, 149]. GL was capable of blocking the chemoattractant as well as mitogenic activities of HMGB1 (Table 1) [142].

GL was capable of binding to both HMG boxes of HMGB1 in both NMR and fluorescence studies without altering their secondary structure, which was observed as an absence of changes in CD spectra [142]. It was further established that amino acids interacting with GL clusters at the junction of both arms of the classical L-shape fold of both HMG boxes in chemical-shift perturbation experiments [142]. Furthermore, the binding sites for GL on the HMG boxes partly overlap with the DNA binding sites, shielding residues like $\mathrm{R} 23$, which is recognized to be crucial for DNA binding [142, 150]. Nevertheless, the RAGE-binding surface on HMGB1 was characterized with the stretch of 
basic amino acids between box $\mathrm{B}$ and the acidic tail and did not match with the binding surfaces of GL $[142,149]$.

Influenza type $\mathrm{A}, \mathrm{B}$, and $\mathrm{C}$ viruses are responsible for influenza infection ("flu") [145]. This infection is often depicted with massive virus replication as well as excessive inflammation [145]. Studies have shown that influenza viruses are capable of infecting monocytes and macrophages resulting in the stimulation of proinflammatory cytokines like TNF- $\alpha$, IL-1, IL-6, IL-8, IFN- $\alpha$, and chemokines in infected areas (Figure 2) $[145,151]$. Moisy et al. demonstrated that HMGB1 binds to the nucleoprotein section of influenza ribonucleoproteins (vRNPs) freely in the company of viral RNA in vitro and interacts with the viral nucleoprotein VCAM-1 in infected cells [152]. They revealed that HMGB1 was capable of facilitating viral growth as well as augmented the transcription or replication activity of the viral polymerase in HMGB1-depleted cells [152]. Thus, HMGB1 binding to DNA was a prerequisite for the augmentation of influenza virus replication [152]. Therefore, GA and GL may be capable of treating influenza viral infection via the HMGB1-TNF- $\alpha$ pathway (Figure 2). Further studies should focus on this pathway.

HMGB1 was able to trigger necrotic cell death resulting in abundant budding of West Nile (WN) progeny virus particles at higher infectious doses [145, 153]. Furthermore, HMGB1 mediated in injurious inflammatory response resulting in the pathogenesis of $\mathrm{WN}$ encephalitis [145, 153, 154]. Besides $\mathrm{WN}$ viruses, other viruses like the salmon anemia virus were capable of triggering necrotic cell death of infected cells, leading to simultaneous HMGB1 expression [145, 154]. GL and GA may be potential treatment options for $\mathrm{WN}$ viral via HMGB1. Further studies are warranted in this direction.

Studies have shown that an increase in proinflammatory cytokines like IL-1, IL-6, TNF- $\alpha$, and IFN- $\gamma$ may trigger the expression of HMGB1 from innate immune cells in SARS patients (Figure 2) [145, 155]. Thus, further studies on GL/GA-HMGB1 axis are needed to elucidate their potential role in the treatment for patients with coronavirus disease19 in the current SARS-coronavirus pandemic. Acute viral hepatitis is caused by hepatitis A, B, C, and D viruses. Their pathogenesis is often depicted with acute necrosis of hepatocytes, inflammation, and followed by fibrosis as well as cirrhosis [145, 156]. HMGB1, passively secreted by necrotic hepatocytes, may stimulate tissue macrophages especially Kupffer cells to express proinflammatory cytokines during an acute infection [145]. Thus, HMGB1 alone or in combination with other proinflammatory cytokines may cause chronic liver damage in hepatitis patients [145]. GL and GA are potential treatment options for chronic viral hepatitis. Further studies are warranted on HMGB1 and/or GL/GA axis.

\section{Conclusion}

GL and GA are able to block the secretion of IL- $1 \beta$, IL-3, IL4, IL-5, IL-6, IL-10, IL-12, IL-13, eotaxin, and TNF- $\alpha$ expression. This means that GL and GA are capable of inhibiting cytokine storms elicited during various infectious diseases most especially viral diseases. GL and GA drastically decreased inflammation via IFN- $\gamma$, which means that GL and GA have very crucial antiviral properties. Also, GA decreased the secretion of VEGF, MCP-1, GM-CSF, and GRO/KC in alcoholic hepatitis rats' models. GA was capable of blocking the modulation of JNK, p38 protein, and ERK in BMMs. Further studies on GL/GA-HMGB1 axis are needed to elucidate their potential role in the treatment for patients with coronavirus disease-19 in the current SARS-coronavirus pandemic.

\section{Abbreviations}

asRNAs: Antisense transcripts

APCs: Antigen-presenting cells

BMMs: $\quad$ Bone marrow-derived macrophages

COX: Cyclooxygenase

GC: $\quad$ Carbenoxolone

CVB3: Coxsackievirus B3

Con A: Concanavalin A

DCs: Dendritic cells

GM-CSF: Granulocyte-macrophage colony-stimulating factor

GL: Glycyrrhizin

GA: $\quad$ Glycyrrhetinic acid

HMGB1: High-mobility group box 1

GRO/KC: Human growth-regulated oncogene/keratinocyte chemoattractant

HIV: Human immunodeficiency virus

ICAM-1: Intercellular cell adhesion molecule 1

IKK: $\quad$ I $\kappa$ B kinase

IFNs: Interferons

IL: Interleukin

iNOS: $\quad$ Inducible nitric oxide synthase

MAPK: $\quad$ Mitogen-activated protein kinase

p38MAPK: p38 mitogen-activated protein kinase

MLR: $\quad$ Mixed lymphocyte reaction

mRNA: Messenger RNA

NK: $\quad$ Natural killer

NO: $\quad$ Nitric oxide

NF- $\kappa$ B: $\quad$ Nuclear factor $-\kappa \mathrm{B}$

NTS: $\quad$ Nitrotyrosine

PLA2: $\quad$ Phospholipase A2

pADR: $\quad$ Poly-adenosine diphosphate-ribose

PMN: $\quad$ Polymorphonuclear neutrophil infiltration

TNF- $\alpha$ : Tumor necrotizing factor- $\alpha$

PGE2: $\quad$ Prostaglandin-E 2

vRNPs: Ribonucleoproteins

TLRs: Toll-like receptors

Th: T-helper

SARS: $\quad$ Severe acute respiratory syndrome

STAT: $\quad$ Signal transducer and activator of transcription

VCAM-1: Vascular adhesion molecule-1

VEGF: Vascular endothelial growth factor

WN: West Nile.

\section{Data Availability}

No data was used in this paper. 


\section{Conflicts of Interest}

The authors declare that they have no conflicts of interest.

\section{References}

[1] N. Abe, T. Ebina, and N. Ishida, "Interferon induction by glycyrrhizin and glycyrrhetinic acid in mice," Microbiology and Immunology, vol. 26, no. 6, pp. 535-539, 1982.

[2] D. Langer, B. Czarczynska-Goslinska, and T. Goslinski, "Glycyrrhetinic acid and its derivatives in infectious diseases," Current Issues in Pharmacy and Medical Sciences, vol. 29, no. 3, pp. 118-123, 2016.

[3] F. Maione, P. Minosi, A. di Giannuario et al., "Long-lasting anti-inflammatory and antinociceptive effects of acute ammonium glycyrrhizinate administration: pharmacological, biochemical, and docking studies," Molecules, vol. 24, no. 13, p. 2453, 2019.

[4] N. Bordbar, M. H. Karimi, and Z. Amirghofran, "The effect of glycyrrhizin on maturation and $\mathrm{T}$ cell stimulating activity of dendritic cells," Cellular Immunology, vol. 280, no. 1, pp. 44-49, 2012.

[5] F. Shamsa, K. Ohtsuki, E. Hasanzadeh, and S. Rezazadeh, "The anti-inflammatory and anti-viral effects of an ethnic medicine: glycyrrhizin," Journal of Medicinal Plants, vol. 9, no. 33, pp. 1-28, 2010.

[6] Y. M. Wang and G. Q. Du, "Glycyrrhizic acid prevents enteritis through reduction of NF- $\kappa$ B p65 and p38MAPK expression in rat," Molecular Medicine Reports, vol. 13, no. 4, pp. 3639-3646, 2016.

[7] J.-M. Crance, F. Lévêque, E. Biziagos, H. van Cuyck-Gandré, A. Jouan, and R. Deloince, "Studies on mechanism of action of glycyrrhizin against hepatitis A virus replication in vitro," Antiviral Research, vol. 23, no. 1, pp. 63-76, 1994.

[8] J. H. Dai, Y. Iwatani, T. Ishida et al., "Glycyrrhizin enhances interleukin-12 production in peritoneal macrophages," Immunology, vol. 103, no. 2, pp. 235-243, 2001.

[9] Y. Zhang, K. Isobe, F. Nagase et al., "Glycyrrhizin as a promoter of the late signal transduction for interleukin-2 production by splenic lymphocytes," Immunology, vol. 79, no. 4, p. 528, 1993.

[10] X. Chen, L. Yang, O. Howard, and J. J. Oppenheim, "Dendritic cells as a pharmacological target of traditional Chinese medicine," Cellular \& Molecular Immunology, vol. 3, no. 6, pp. 401-410, 2006.

[11] T. Okamoto, "The protective effect of glycyrrhizin on antiFas antibody-induced hepatitis in mice," European Journal of Pharmacology, vol. 387, no. 2, pp. 229-232, 2000.

[12] B. Ploeger, T. Mensinga, A. Sips, W. Seinen, J. Meulenbelt, and J. DeJongh, "The pharmacokinetics of glycyrrhizic acid evaluated by physiologically based pharmacokinetic modeling," Drug Metabolism Reviews, vol. 33, no. 2, pp. 125-147, 2001.

[13] G. Fenwick, J. Lutomski, and C. Nieman, "Liquorice, Glycyrrhiza glabra L. -Composition, uses and analysis," Food Chemistry, vol. 38, no. 2, pp. 119-143, 1990.

[14] L. J. Ming and A. C. Y. Yin, "Therapeutic effects of glycyrrhizic acid," Natural Product Communications, vol. 8, no. 3, article 1934578X1300800335, 2013.

[15] T. V. Rossum, Vulto, R. A. D. Man, Brouwer, and Schalm, "Glycyrrhizin as a potential treatment for chronic hepatitis
C," Alimentary Pharmacology \& Therapeutics, vol. 12, no. 3, pp. 199-205, 1998.

[16] U. A. Ashfaq, M. S. Masoud, Z. Nawaz, and S. Riazuddin, "Glycyrrhizin as antiviral agent against hepatitis C virus," Journal of Translational Medicine, vol. 9, no. 1, article 800, pp. 1-7, 2011.

[17] L. Baltina, R. Kondratenko, L. A. Baltina Jr., O. A. Plyasunova, A. G. Pokrovskii, and G. A. Tolstikov, "Prospects for the creation of new antiviral drugs based on glycyrrhizic acid and its derivatives (a review)," Pharmaceutical Chemistry Journal, vol. 43, no. 10, article 348, pp. 539-548, 2009.

[18] C. Fiore, M. Eisenhut, R. Krausse et al., "Antiviral effects ofGlycyrrhiza species," Phytotherapy Research, vol. 22, no. 2, pp. 141-148, 2008.

[19] S. Harada, T. Maekawa, E. Haneda, Y. Morikawa, N. Nagata, and K. Ohtsuki, "Biochemical characterization of recombinant HIV-1 reverse transcriptase (rRT) as a glycyrrhizin-binding protein and the CK-II-mediated stimulation of rRT activity potently inhibited by glycyrrhetinic acid derivative," Biological and Pharmaceutical Bulletin, vol. 21, no. 12, pp. 1282-1285, 1998.

[20] L. Wang, R. Yang, B. Yuan, Y. Liu, and C. Liu, "The antiviral and antimicrobial activities of licorice, a widely-used Chinese herb," Acta Pharmaceutica Sinica B, vol. 5, no. 4, pp. 310315, 2011.

[21] M. H. Salari, S. Eshraghi, and M. Noroozi, "Antibacterial effect of glycyrrhetinic acid on 55 hospital strains of staphylococcus aureus and 32 actinobacillus actinomycetemcomitans," DARU Journal of Pharmaceutical Sciences, vol. 9, no. 3-4, pp. 37-39, 2001.

[22] M. M. Nitalikar, K. C. Munde, B. V. Dhore, and S. N. Shikalgar, "Studies of antibacterial activities of Glycyrrhiza glabra root extract," International Journal of PharmTech Research, vol. 2, no. 1, pp. 899-901, 2010.

[23] M. Salari and Z. Kadkhoda, "In vitro antibacterial effects of glycyrrhetinic acid on periodontopathogenic and capnophilic bacteria isolated from adult periodontitis," Clinical Microbiology and Infection, vol. 9, no. 9, pp. 987-988, 2003.

[24] I. A. Rodrigues, A. M. Mazotto, V. Cardoso et al., "Natural products: insights into leishmaniasis inflammatory response," Mediators of Inflammation, vol. 2015, Article ID 835910, 12 pages, 2015.

[25] S. Bhattacharjee, A. Bhattacharjee, S. Majumder, S. B. Majumdar, and S. Majumdar, "Glycyrrhizic acid suppresses Cox-2-mediated anti-inflammatory responses during Leishmania donovani infection," Journal of Antimicrobial Chemotherapy, vol. 67, no. 8, pp. 1905-1914, 2012.

[26] S. Krähenbühl, F. Hasler, B. M. Frey, F. J. Frey, R. Brenneisen, and R. Krapf, "Kinetics and dynamics of orally administered 18 beta-glycyrrhetinic acid in humans," The Journal of Clinical Endocrinology \& Metabolism, vol. 78, no. 3, pp. 581-585, 1994.

[27] T. Akao, "Localization of enzymes involved in metabolism of glycyrrhizin in contents of rat gastrointestinal tract," Biological and Pharmaceutical Bulletin, vol. 20, no. 2, pp. 122-126, 1997.

[28] T. Akao, T. Akao, and K. Kobashi, "Glycyrrhizin $\beta$-D-glucuronidase of Eubacterium sp. from human intestinal flora," Chemical and Pharmaceutical Bulletin, vol. 35, no. 2, pp. 705-710, 1987.

[29] M. Hattori, T. Sakamoto, K. Kobashi, and T. Namba, "Metabolism of glycyrrhizin by human intestinal flora," Planta Medica, vol. 48, no. 5, pp. 38-42, 1983. 
[30] M. Michaelis, J. Geiler, P. Naczk et al., “Glycyrrhizin inhibits highly pathogenic $\mathrm{H} 5 \mathrm{~N} 1$ influenza A virus-induced proinflammatory cytokine and chemokine expression in human macrophages," Medical Microbiology and Immunology, vol. 199, no. 4, pp. 291-297, 2010.

[31] T. G. van Rossum, A. G. Vulto, W. C. Hop, and S. W. Schalm, "Pharmacokinetics of intravenous glycyrrhizin after single and multiple doses in patients with chronic hepatitis $\mathrm{C}$ infection," Clinical Therapeutics, vol. 21, no. 12, pp. 2080-2090, 1999.

[32] S. Ishida, Y. Sakiya, T. Ichikawa, and S. AwAzu, "Pharmacokinetics of glycyrrhetic acid, a major metabolite of glycyrrhizin, in rats," Chemical and Pharmaceutical Bulletin, vol. 37, no. 9, pp. 2509-2513, 1989.

[33] F. Størmer, R. Reistad, and J. Alexander, "Glycyrrhizic acid in liquorice-evaluation of health hazard," Food and Chemical Toxicology, vol. 31, no. 4, pp. 303-312, 1993.

[34] B. R. Walker and C. R. Edwards, "Licorice-induced hypertension and syndromes of apparent mineralocorticoid excess," Endocrinology and Metabolism Clinics of North America, vol. 23, no. 2, pp. 359-377, 1994.

[35] K. T. Feehan and D. W. Gilroy, "Is resolution the end of inflammation?," Trends in Molecular Medicine, vol. 25, no. 3, pp. 198-214, 2019.

[36] M. P. Manns, H. Wedemeyer, A. Singer et al., "Glycyrrhizin in patients who failed previous interferon alpha-based therapies: biochemical and histological effects after 52 weeks," Journal of Viral Hepatitis, vol. 19, no. 8, pp. 537-546, 2012.

[37] K. Ohtsuki, Y. Abe, Y. Shimoyama, T. Furuya, H. Munakata, and C. Takasaki, "Separation of phospholipase A2 in Habu snake venom by glycyrrhizin (GL)-affinity column chromatography and identification of a GL-sensitive enzyme," Biological and Pharmaceutical Bulletin, vol. 21, no. 6, pp. 574578, 1998.

[38] Y. Shimoyama, H. Ohtaka, N. Nagata, H. Munakata, N. Hayashi, and K. Ohtsuki, "Physiological correlation between glycyrrhizin, glycyrrhizin-binding lipoxygenase and casein kinase II," FEBS Letters, vol. 391, no. 3, pp. 238-242, 1996.

[39] S. Matsui, H. Matsumoto, Y. Sonoda et al., "Glycyrrhizin and related compounds down-regulate production of inflammatory chemokines IL- 8 and eotaxin 1 in a human lung fibroblast cell line," International Immunopharmacology, vol. 4, no. 13, pp. 1633-1644, 2004.

[40] X. Huo, X. Sun, Z. Cao et al., "Optimal ratio of $18 \alpha$-and $18 \beta$ glycyrrhizic acid for preventing alcoholic hepatitis in rats," Experimental and Therapeutic Medicine, vol. 18, no. 1, pp. 172-178, 2019.

[41] R. Yang, B.-C. Yuan, Y.-S. Ma, S. Zhou, and Y. Liu, “The antiinflammatory activity of licorice, a widely used Chinese herb," Pharmaceutical Biology, vol. 55, no. 1, pp. 5-18, 2017.

[42] C. Xie, X. Li, J. Wu et al., "Anti-inflammatory activity of magnesium isoglycyrrhizinate through inhibition of phospholipase A2/arachidonic acid pathway," Inflammation, vol. 38, no. 4, pp. 1639-1648, 2015.

[43] Z. Xiao, W. Zhang, L. Ma, and Z. Qiu, "Therapeutic effect of magnesium isoglycyrrhizinate in rats on lung injury induced by paraquat poisoning," European Review for Medical and Pharmacological Sciences, vol. 18, no. 3, pp. 311-320, 2014.

[44] X. Huang, J. Qin, and S. Lu, "Magnesium isoglycyrrhizinate protects hepatic L02 cells from ischemia/reperfusion induced injury," International Journal of Clinical and Experimental Pathology, vol. 7, no. 8, p. 4755, 2014.

[45] J. Y. Li, H. Y. Cao, P. Liu, G. H. Cheng, and M. Y. Sun, “Glycyrrhizic acid in the treatment of liver diseases: literature review," BioMed Research International, vol. 2014, Article ID 872139, 15 pages, 2014.

[46] B. Schröfelbauer, J. Raffetseder, M. Hauner, A. Wolkerstorfer, W. Ernst, and O. H. Szolar, "Glycyrrhizin, the main active compound in liquorice, attenuates pro-inflammatory responses by interfering with membrane-dependent receptor signalling," Biochemical Journal, vol. 421, no. 3, pp. 473-482, 2009.

[47] H. Honda, Y. Nagai, T. Matsunaga et al., "Glycyrrhizin and isoliquiritigenin suppress the LPS sensor toll-like receptor 4/MD-2 complex signaling in a different manner," Journal of Leukocyte Biology, vol. 91, no. 6, pp. 967-976, 2012.

[48] R. M. Steinman, B. Gutchinov, M. D. Witmer, and M. C. Nussenzweig, "Dendritic cells are the principal stimulators of the primary mixed leukocyte reaction in mice," The Journal of Experimental Medicine, vol. 157, no. 2, pp. 613-627, 1983.

[49] K. Liu and M. C. Nussenzweig, "Development and homeostasis of dendritic cells," European Journal of Immunology, vol. 40, no. 8, pp. 2099-2102, 2010.

[50] M. Collin and V. Bigley, "Human dendritic cell subsets: an update," Immunology, vol. 154, no. 1, pp. 3-20, 2018.

[51] R. Tisch, "Immunogenic versus tolerogenic dendritic cells: a matter of maturation," International Reviews of Immunology, vol. 29, no. 2, pp. 111-118, 2010.

[52] T. Miloud, G. J. Hämmerling, and N. Garbi, "Review of murine dendritic cells: types, location, and development," in Dendritic Cell Protocols, pp. 21-42, Springer, 2010.

[53] A. Azadmehr, A. A. Pourfathollah, Z. Amirghofran, Z. M. Hassan, and S. M. Moazzeni, "Enhancement of Th1 immune response by $\mathrm{CD} 8 \alpha+$ dendritic cells loaded with heat shock proteins enriched tumor extract in tumor-bearing mice," Cellular Immunology, vol. 260, no. 1, pp. 28-32, 2009.

[54] M. Abe, F. Akbar, A. Hasebe, N. Horiike, and M. Onji, "Glycyrrhizin enhances interleukin-10 production by liver dendritic cells in mice with hepatitis," Journal of Gastroenterology, vol. 38, no. 10, pp. 962-967, 2003.

[55] H. Hua, Z. Liang, W. Li et al., "Phenotypic and functional maturation of murine dendritic cells (DCs) induced by purified Glycyrrhizin (GL)," International Immunopharmacology, vol. 12, no. 3, pp. 518-525, 2012.

[56] A. Ukil, A. Biswas, T. Das, and P. K. Das, " $18 \beta$-glycyrrhetinic acid triggers curative Th1 response and nitric oxide upregulation in experimental visceral leishmaniasis associated with the activation of NF- $\kappa \mathrm{B}$," The Journal of Immunology, vol. 175, no. 2, pp. 1161-1169, 2005.

[57] P. Takk and G. Firestein, "NF- $\kappa$ B: a key role in inflammatory disease," Journal of Clinical Investigation, vol. 107, pp. 7-11, 2001.

[58] A. S. Baldwin Jr., "The NF- $\kappa$ B and $\mathrm{I} \kappa \mathrm{B}$ proteins: new discoveries and insights," Annual review of immunology, vol. 14, no. 1, pp. 649-681, 1996.

[59] S. S. Makarov, "NF- $\kappa \mathrm{B}$ as a therapeutic target in chronic inflammation: recent advances," Molecular medicine today, vol. 6, no. 11, pp. 441-448, 2000.

[60] A. S. Baldwin, "Series introduction: the transcription factor NF- $\kappa \mathrm{B}$ and human disease," The Journal of clinical investigation, vol. 107, no. 1, pp. 3-6, 2001. 
[61] M. J. May and S. Ghosh, "Signal transduction through NF$\kappa \mathrm{B}$," Immunology Today, vol. 19, no. 2, pp. 80-88, 1998.

[62] S. Ghosh and M. Karin, "Missing pieces in the NF- $\kappa$ B puzzle," Cell, vol. 109, no. 2, pp. S81-S96, 2002.

[63] F. Mercurio and A. M. Manning, "Multiple signals converging on NF- $\kappa \mathrm{B}$," Current Opinion in Cell Biology, vol. 11, no. 2, pp. 226-232, 1999.

[64] H. Zhang, Y. Song, and Z. Zhang, "Glycyrrhizin administration ameliorates coxsackievirus B3-induced myocarditis in mice," The American journal of the medical sciences, vol. 344, no. 3, pp. 206-210, 2012.

[65] J.-M. Cherng, K.-D. Tsai, Y.-W. Yu, and J.-C. Lin, "Molecular mechanisms underlying chemopreventive activities of glycyrrhizic acid against UVB-radiation-induced carcinogenesis in SKH-1 hairless mouse epidermis," Radiation Research, vol. 176, no. 2, pp. 177-186, 2011.

[66] L. Feng, M.-m. Zhu, M.-h. Zhang et al., "Protection of glycyrrhizic acid against AGEs-induced endothelial dysfunction through inhibiting $\mathrm{RAGE} / \mathrm{NF}-\kappa \mathrm{B}$ pathway activation in human umbilical vein endothelial cells," Journal of ethnopharmacology, vol. 148, no. 1, pp. 27-36, 2013.

[67] J. Park, K. Choi, E. Jeong, D. Kwon, E. N. Benveniste, and C. Choi, "Reactive oxygen species mediate chloroquineinduced expression of chemokines by human astroglial cells," Glia, vol. 47, no. 1, pp. 9-20, 2004.

[68] W. J. Streit, J. R. Conde, and J. K. Harrison, "Chemokines and Alzheimer's disease," Neurobiology of aging, vol. 22, no. 6, pp. 909-913, 2001.

[69] A. Bajetto, R. Bonavia, S. Barbero, T. Florio, and G. Schettini, "Chemokines and their receptors in the central nervous system," Frontiers in neuroendocrinology, vol. 22, no. 3, pp. 147-184, 2001.

[70] H. Soufy, S. Yassein, A. R. Ahmed et al., "Antiviral and immune stimulant activities of glycyrrhizin against duck hepatitis virus," African Journal of Traditional, Complementary and Alternative Medicines, vol. 9, no. 3, pp. 389-395, 2012.

[71] M. D. de Jong, C. P. Simmons, T. T. Thanh et al., "Fatal outcome of human influenza A (H5N1) is associated with high viral load and hypercytokinemia," Nature medicine, vol. 12, no. 10, pp. 1203-1207, 2006.

[72] P. Jose, D. Griffiths-Johnson, P. Collins et al., "Eotaxin: a potent eosinophil chemoattractant cytokine detected in a guinea pig model of allergic airways inflammation," The Journal of experimental medicine, vol. 179 , no. 3, pp. 881-887, 1994.

[73] M. Kitaura, T. Nakajima, T. Imai et al., "Molecular cloning of human eotaxin, an eosinophil-selective CC chemokine, and identification of a specific eosinophil eotaxin receptor, CC chemokine receptor 3," Journal of Biological Chemistry, vol. 271, no. 13, pp. 7725-7730, 1996.

[74] L. M. Teran, M. Mochizuki, J. Bartels et al., "Th1-and Th2type cytokines regulate the expression and production of eotaxin and RANTES by human lung fibroblasts," American journal of respiratory cell and molecular biology, vol. 20, no. 4, pp. 777-786, 1999.

[75] M. Miyamasu, T. Nakajima, Y. Misaki et al., "Dermal fibroblasts represent a potent major source of human eotaxin: in vitro production and cytokine-mediated regulation," Cytokine, vol. 11, no. 10, pp. 751-758, 1999.

[76] S. Matsui, Y. Sonoda, T. Sekiya, E. Aizu-Yokota, and T. Kasahara, "Glycyrrhizin derivative inhibits eotaxin 1 pro- duction via STAT6 in human lung fibroblasts," International immunopharmacology, vol. 6, no. 3, pp. 369-375, 2006.

[77] S. Matsukura, C. Stellato, J. R. Plitt et al., "Activation of eotaxin gene transcription by NF-kappa B and STAT6 in human airway epithelial cells," The Journal of Immunology, vol. 163, no. 12, pp. 6876-6883, 1999.

[78] J. Hoeck and M. Woisetschläger, "STAT6 mediates eotaxin-1 expression in IL-4 or TNF- $\alpha$-induced fibroblasts," The Journal of Immunology, vol. 166, no. 7, pp. 4507-4515, 2001.

[79] L. Malmgaard, "Induction and regulation of IFNs during viral infections," Journal of interferon \& cytokine research, vol. 24, no. 8, pp. 439-454, 2004.

[80] G. C. Sen, "Viruses and interferons," Annual Reviews in Microbiology, vol. 55, no. 1, pp. 255-281, 2001.

[81] C.-F. Huang, T.-C. Wu, C.-C. Wu et al., "Sublingual vaccination with sonicated Salmonella proteins and mucosal adjuvant induces mucosal and systemic immunity and protects mice from lethal enteritis," Apmis, vol. 119, no. 7, pp. 468-478, 2011.

[82] J. K. Dunnick and G. J. Galasso, "Update on clinical trials with exogenous interferon," The Journal of infectious diseases, vol. 142, no. 2, pp. 293-299, 1980.

[83] H. B. Greenberg, R. B. Pollard, L. I. Lutwick, P. B. Gregory, W. S. Robinson, and T. C. Merigan, "Effect of human leukocyte interferon on hepatitis B virus infection in patients with chronic active hepatitis," New England Journal of Medicine, vol. 295, no. 10, pp. 517-522, 1976.

[84] S. Matsubara, M. Suzuki, F. Suzuki, and N. Ishida, "The induction of viral inhibitor (s) in mice treated with biological and synthetic immunopotentiators," Microbiology and immunology, vol. 24, no. 1, pp. 87-90, 1980.

[85] Y. Kondo and F. Takano, "Nitric oxide production in mouse peritoneal macrophages enhanced with glycyrrhizin," Biological and Pharmaceutical Bulletin, vol. 17, no. 5, pp. 759-761, 1994.

[86] M. Shinada, M. Azuma, H. Kawai et al., "Enhancement of interferon- $\gamma$ production in glycyrrhizin-treated human peripheral lymphocytes in response to concanavalin A and to surface antigen of hepatitis B virus," Proceedings of the society for experimental biology and medicine, vol. 181, no. 2, pp. 205-210, 1986.

[87] J. Y. Djeu, J. A. Heinbaugh, H. T. Holden, and R. B. Herberman, "Augmentation of mouse natural killer cell activity by interferon and interferon inducers," The Journal of Immunology, vol. 122, no. 1, pp. 175-181, 1979.

[88] R. M. Schultz, J. D. Papamatheakis, and M. A. Chirigos, "Interferon: an inducer of macrophage activation by polyanions," Science, vol. 197, no. 4304, pp. 674-676, 1977.

[89] Q. Wu, Y. Tang, J. Zhang, X. Hu, Q. Wang, and J. Huang, "Therapeutic effects of glycyrrhizic acid on asthma airway inflammation in mice and its mechanism," Zhonghua yi xue za zhi, vol. 94, no. 42, pp. 3338-3344, 2014.

[90] F. Fitzpatrick, "Cyclooxygenase enzymes: regulation and function," Current pharmaceutical design, vol. 10, no. 6, pp. 577-588, 2004.

[91] J. Li, G. Feng, J. Liu et al., "Renal cell carcinoma may evade the immune system by converting CD4+ Foxp3-T cells into CD4+ CD25+ Foxp3+ regulatory $\mathrm{T}$ cells: Role of tumor COX-2-derived PGE2," Molecular medicine reports, vol. 3, no. 6, pp. 959-963, 2010.

[92] L. Sun, J. Liu, D. Cui et al., "Anti-inflammatory function of Withangulatin A by targeted inhibiting COX-2 expression 
via MAPK and NF- $\kappa$ B pathways," Journal of cellular biochemistry, vol. 109, no. 3, pp. 532-541, 2009.

[93] M. Olivier, D. J. Gregory, and G. Forget, "Subversion mechanisms by which Leishmania parasites can escape the host immune response: a signaling point of view," Clinical microbiology reviews, vol. 18, no. 2, pp. 293-305, 2005.

[94] C. E. Trebino, J. L. Stock, C. P. Gibbons et al., "Impaired inflammatory and pain responses in mice lacking an inducible prostaglandin E synthase," Proceedings of the National Academy of Sciences, vol. 100, no. 15, pp. 9044-9049, 2003.

[95] C. S. Williams, M. Mann, and R. N. DuBois, "The role of cyclooxygenases+ in inflammation, cancer, and development," Oncogene, vol. 18, no. 55, pp. 7908-7916, 1999.

[96] M. Betz and B. Fox, "Prostaglandin E2 inhibits production of Th1 lymphokines but not of Th2 lymphokines," The Journal of Immunology, vol. 146, no. 1, pp. 108-113, 1991.

[97] H.-G. Klingemann, M.-S. Tsoi, and R. Storb, "Inhibition of prostaglandin E2 restores defective lymphocyte proliferation and cell-mediated lympholysis in recipients after allogeneic marrow grafting," Blood, vol. 68, no. 1, pp. 102-107, 1986.

[98] Y.-F. Ni, J.-K. Kuai, Z.-F. Lu et al., "Glycyrrhizin treatment is associated with attenuation of lipopolysaccharide-induced acute lung injury by inhibiting cyclooxygenase- 2 and inducible nitric oxide synthase expression," Journal of Surgical Research, vol. 165, no. 1, pp. e29-e35, 2011.

[99] W. Ouyang and A. O’Garra, "IL-10 family cytokines IL-10 and IL-22: from basic science to clinical translation," Immunity, vol. 50, no. 4, pp. 871-891, 2019.

[100] R. Manetti, P. Parronchi, M. G. Giudizi et al., "Natural killer cell stimulatory factor (interleukin 12 [IL-12]) induces $\mathrm{T}$ helper type 1 (Th1)-specific immune responses and inhibits the development of IL-4-producing Th cells," The Journal of experimental medicine, vol. 177, no. 4, pp. 1199-1204, 1993.

[101] G. Trinchieri, "Interleukin-12 and its role in the generation of TH1 cells," Immunology today, vol. 14, no. 7, pp. 335-338, 1993.

[102] J. Chehimi, S. E. Starr, I. Frank et al., "Impaired interleukin 12 production in human immunodeficiency virus-infected patients," The Journal of experimental medicine, vol. 179, no. 4, pp. 1361-1366, 1994.

[103] J. Chehimi, S. E. Starr, I. Frank et al., "Natural killer (NK) cell stimulatory factor increases the cytotoxic activity of NK cells from both healthy donors and human immunodeficiency virus-infected patients," The Journal of experimental medicine, vol. 175, no. 3, pp. 789-796, 1992.

[104] G. Trinchieri, "Interleukin-12: a cytokine produced by antigen-presenting cells with immunoregulatory functions in the generation of T-helper cells type 1 and cytotoxic lymphocytes," Blood, vol. 84, no. 12, pp. 4008-4027, 1994.

[105] Z. Liu, J. Y. Zhong, E. N. Gao, and H. Yang, "Effects of glycyrrhizin acid and licorice flavonoids on LPS-induced cytokines expression in macrophage," Zhongguo Zhong Yao Za Zhi, vol. 39, no. 19, pp. 3841-3845, 2014.

[106] T. Raphael and G. Kuttan, "Effect of naturally occurring triterpenoids glycyrrhizic acid, ursolic acid, oleanolic acid and nomilin on the immune system," Phytomedicine, vol. 10, no. 6-7, pp. 483-489, 2003.

[107] Y.-H. Zhang, M. Kato, K.-I. Isobe, M. Hamaguchi, T. Yokochi, and I. Nakashima, "Dissociated control by glycyrrhizin of proliferation and IL-2 production of murine thy- mocytes," Cellular immunology, vol. 162, no. 1, pp. 97-104, 1995.

[108] B. Jaruga, F. Hong, R. Sun, S. Radaeva, and B. Gao, "Crucial role of IL-4/STAT6 in T cell-mediated hepatitis: upregulating eotaxins and IL-5 and recruiting leukocytes," The Journal of Immunology, vol. 171, no. 6, pp. 3233-3244, 2003.

[109] A. M. Miller, N. Horiguchi, W. I. Jeong, S. Radaeva, and B. Gao, "Molecular mechanisms of alcoholic liver disease: innate immunity and cytokines," Alcoholism: Clinical and Experimental Research, vol. 35, no. 5, pp. 787-793, 2011.

[110] K. C. El Kasmi, A. M. Smith, L. Williams et al., "Cutting edge: a transcriptional repressor and corepressor induced by the STAT3-regulated anti-inflammatory signaling pathway," The Journal of Immunology, vol. 179, no. 11, pp. 7215-7219, 2007.

[111] T. Yoshida, K. Abe, T. Ikeda et al., "Inhibitory effect of glycyrrhizin on lipopolysaccharide and d-galactosamine-induced mouse liver injury," European journal of pharmacology, vol. 576, pp. 136-142, 2007.

[112] K. Nakanishi, T. Yoshimoto, H. Tsutsui, and H. Okamura, "Interleukin-18 regulates both Th1 and Th2 responses," Annual review of immunology, vol. 19, no. 1, pp. 423-474, 2001.

[113] K.-R. Park, D. Nam, H.-M. Yun et al., " $\beta$-Caryophyllene oxide inhibits growth and induces apoptosis through the suppression of PI3K/AKT/mTOR/S6K1 pathways and ROSmediated MAPKs activation," Cancer Letter, vol. 312, no. 2, pp. 178-188, 2011.

[114] C.-K. Kim, Y. K. Choi, H. Lee et al., "The farnesyltransferase inhibitor LB42708 suppresses vascular endothelial growth factor-induced angiogenesis by inhibiting ras-dependent mitogen-activated protein kinase and phosphatidylinositol 3-kinase/Akt signal pathways," Molecular pharmacology, vol. 78, no. 1, pp. 142-150, 2010.

[115] Z.-h. Wang, C.-. H. Hsieh, W.-h. Liu, and M.-c. Yin, "Glycyrrhizic acid attenuated glycative stress in kidney of diabetic mice through enhancing glyoxalase pathway," Molecular nutrition \& food research, vol. 58, no. 7, pp. 1426-1435, 2014.

[116] M. Wojcik, A. Zieleniak, M. Zurawska-Klis, K. Cypryk, and L. A. Wozniak, "Increased expression of immune-related genes in leukocytes of patients with diagnosed gestational diabetes mellitus (GDM)," Experimental Biology and Medicine, vol. 241, no. 5, pp. 457-465, 2016.

[117] R. Tanemoto, T. Okuyama, H. Matsuo, T. Okumura, Y. Ikeya, and M. Nishizawa, "The constituents of licorice (Glycyrrhiza uralensis) differentially suppress nitric oxide production in interleukin- $1 \beta$-treated hepatocytes," Biochemistry and biophysics reports, vol. 2, pp. 153-159, 2015.

[118] A. Nakajima, Y. Yamamoto, N. Yoshinaka et al., "A new flavanone and other flavonoids from green perilla leaf extract inhibit nitric oxide production in interleukin $1 \beta$-treated hepatocytes," Bioscience, biotechnology, and biochemistry, vol. 79, no. 1, pp. 138-146, 2015.

[119] N. Tsuruoka, K. Abe, K. Wake et al., "Hepatic protection by glycyrrhizin and inhibition of iNOS expression in concanavalin A-induced liver injury in mice," Inflammation Research, vol. 58, no. 9, pp. 593-599, 2009.

[120] Y. Tanaka, M. Kaibori, H. Miki et al., "Japanese Kampo medicine, ninjinyoeito, inhibits the induction of iNOS gene expression in proinflammatory cytokine-stimulated hepatocytes," British Journal of Pharmaceutical Research, vol. 4, pp. 2226-2244, 2014. 
[121] M. Colasanti and H. Suzuki, "The dual personality of NO," Trends Pharmacology Science, vol. 21, no. 7, pp. 249-252, 2000.

[122] K. Matsui, M. Nishizawa, T. Ozaki et al., "Natural antisense transcript stabilizes inducible nitric oxide synthase messenger RNA in rat hepatocytes," Hepatology, vol. 47, no. 2, pp. 686697, 2007.

[123] M. Nishizawa, Y. Ikeya, T. Okumura, and T. Kimura, "Posttranscriptional inducible gene regulation by natural antisense RNA," Frontiers in Bioscience, vol. 20, pp. 1-36, 2015.

[124] T. Kanemaki, H. Kitade, Y. Hiramatsu, Y. Kamiyama, and T. Okumura, "Stimulation of glycogen degradation by prostaglandin E2 in primary cultured rat hepatocytes," Prostaglandins, vol. 45, no. 5, pp. 459-474, 1993.

[125] B. Jaruga, F. Hong, W.-H. Kim, and B. Gao, "IFN- $\gamma /$ STAT1 acts as a proinflammatory signal in T cell-mediated hepatitis via induction of multiple chemokines and adhesion molecules: a critical role of IRF-1," American Journal of Physiology-Gastrointestinal and Liver Physiology, vol. 287, no. 5, pp. G1044-G1052, 2004.

[126] T. Okamoto and T. Kanda, "Glycyrrhizin protects mice from concanavalin A-induced hepatitis without affecting cytokine expression," International journal of molecular medicine, vol. 4, no. 2, pp. 149-201, 1999.

[127] C.-H. Lee, S.-W. Park, Y. S. Kim et al., "Protective mechanism of glycyrrhizin on acute liver injury induced by carbon tetrachloride in mice," Biological and Pharmaceutical Bulletin, vol. 30, no. 10, pp. 1898-1904, 2007.

[128] K. Takeda, T. Kaisho, and S. Akira, "Toll-like receptors," Annual review of immunology, vol. 21, no. 1, pp. 335-376, 2015.

[129] X. Shi, L. Yu, Y. Zhang et al., "Glycyrrhetinic acid alleviates hepatic inflammation injury in viral hepatitis disease via a HMGB1-TLR4 signaling pathway," International immunopharmacology, vol. 84, no. 106578, pp. 1-12, 2020.

[130] J. B. Williams, A. Hüppner, P. M. Mulrooney-Cousins, and T. I. Michalak, "Differential expression of woodchuck tolllike receptors 1-10 in distinct forms of infection and stages of hepatitis in experimental hepatitis B virus infection," Frontiers in microbiology, vol. 9, 2018.

[131] P. Gupta, P. K. Das, and A. Ukil, "Antileishmanial effect of $18 \beta$-glycyrrhetinic acid is mediated by toll-like receptordependent canonical and noncanonical p38 activation," Antimicrobial agents and chemotherapy, vol. 59, no. 5, pp. 25312539, 2015.

[132] L.-N. Peng, L. Li, Y.-F. Qiu et al., "Glycyrrhetinic acid extracted from Glycyrrhiza uralensis Fisch. induces the expression of toll-like receptor 4 in Ana-1 murine macrophages," Journal of Asian natural products research, vol. 13, no. 10, pp. 942-950, 2011.

[133] C. S. Graebin, "The pharmacological activities of glycyrrhizinic acid ("glycyrrhizin") and glycyrrhetinic acid," Reference Series in Phytochemistry, pp. 245-261, 2018.

[134] W. Liu, S. Huang, Y. Li, K. Zhang, and X. Zheng, "Suppressive effect of glycyrrhizic acid against lipopolysaccharide-induced neuroinflammation and cognitive impairment in C57 mice via toll-like receptor 4 signaling pathway," Food \& nutrition research, vol. 63, 2019.

[135] N. F. Abo El-Magd, A. El-Karef, M. M. El-Shishtawy, and L. A. Eissa, "Glycyrrhizin and Omega-3 fatty acids have hepatoprotective roles through toll-like receptor-4," Egyptian
Journal of Basic and Applied Sciences, vol. 6, no. 1, pp. 8298, 2019.

[136] M. Loiarro, V. Ruggiero, and C. Sette, "Targeting TLR/IL-1R signalling in human diseases," Mediators of inflammation, vol. 2010, Article ID 674363, 12 pages, 2010.

[137] K. A. Shirey, W. Lai, M. C. Patel et al., "Novel strategies for targeting innate immune responses to influenza," Mucosal immunology, vol. 9, no. 5, pp. 1173-1182, 2016.

[138] M. G. Morale, W. da Silva Abjaude, A. M. Silva, L. L. Villa, and E. Boccardo, "HPV-transformed cells exhibit altered HMGB1-TLR4/MyD88-SARM1 signaling axis," Scientific reports, vol. 8, no. 1, pp. 1-11, 2018.

[139] K. Rayavara, A. Kurosky, S. J. Stafford et al., "Proinflammatory effects of respiratory syncytial virus-induced epithelial HMGB1 on human innate immune cell activation," The Journal of Immunology, vol. 201, no. 9, pp. 2753-2766, 2018.

[140] G. W. Nace, H. Huang, J. R. Klune et al., "Cellular-specific role of toll-like receptor 4 in hepatic ischemia-reperfusion injury in mice," Hepatology, vol. 58, no. 1, pp. 374-387, 2013.

[141] R. Gao, Y. Zhang, Y. Kang et al., "Glycyrrhizin inhibits PEDV infection and proinflammatory cytokine secretion via the HMGB1/TLR4-MAPK p38 pathway," International journal of molecular sciences, vol. 21, no. 8, p. 2961, 2020.

[142] L. Mollica, F. De Marchis, A. Spitaleri et al., "Glycyrrhizin binds to high-mobility group box 1 protein and inhibits its cytokine activities," Chemistry \& biology, vol. 14, no. 4, pp. 431-441, 2007.

[143] M. E. Bianchi and A. Agresti, "HMG proteins: dynamic players in gene regulation and differentiation," Current opinion in genetics \& development, vol. 15, no. 5, pp. 496-506, 2005.

[144] H. Wang, O. Bloom, M. Zhang et al., "HMG-1 as a late mediator of endotoxin lethality in mice," Science, vol. 285, no. 5425, pp. 248-251, 1999.

[145] H. Wang, M. F. Ward, X.-G. Fan, A. E. Sama, and W. Li, "Potential role of high mobility group box 1 in viral infectious diseases," Viral immunology, vol. 19, no. 1, pp. 3-9, 2006.

[146] U. Andersson, H. Wang, K. Palmblad et al., "High mobility group 1 protein (HMG-1) stimulates proinflammatory cytokine synthesis in human monocytes," Journal of Experimental Medicine, vol. 192, no. 4, pp. 565-570, 2000.

[147] G. Chen, D.-z. Chen, J. Li et al., "Pathogenic role of HMGB1 in SARS?," Medical hypotheses, vol. 63, no. 4, pp. 691-695, 2004.

[148] C. Fiuza, M. Bustin, S. Talwar et al., "Inflammation-promoting activity of HMGB1 on human microvascular endothelial cells," Blood, The Journal of the American Society of Hematology, vol. 101, no. 7, pp. 2652-2660, 2003.

[149] R. Palumbo, M. Sampaolesi, F. De Marchis et al., "Extracellular HMGB1, a signal of tissue damage, induces mesoangioblast migration and proliferation," The Journal of cell biology, vol. 164, no. 3, pp. 441-449, 2004.

[150] U.-M. Ohndorf, M. A. Rould, Q. He, C. O. Pabo, and S. J. Lippard, "Basis for recognition of cisplatin-modified DNA by high-mobility-group proteins," Nature, vol. 399, no. 6737, pp. 708-712, 1999.

[151] I. Julkunen, T. Sareneva, J. Pirhonen, T. Ronni, K. Melén, and S. Matikainen, "Molecular pathogenesis of influenza A virus infection and virus-induced regulation of cytokine gene expression," Cytokine Growth Factor Rev, vol. 12, no. 2-3, pp. 171-180, 2001. 
[152] D. Moisy, S. V. Avilov, Y. Jacob et al., "HMGB1 protein binds to influenza virus nucleoprotein and promotes viral replication," Journal of virology, vol. 86, no. 17, pp. 9122-9133, 2012.

[153] J. Chu and M. Ng, "The mechanism of cell death during West Nile virus infection is dependent on initial infectious dose," Journal of General Virology, vol. 84, no. 12, pp. 3305-3314, 2003.

[154] T. Joseph, A. Cepica, L. Brown, B. O. Ikede, and F. S. Kibenge, "Mechanism of cell death during infectious salmon anemia virus infection is cell type-specific," Journal of General Virology, vol. 85, no. 10, pp. 3027-3036, 2004.

[155] J. F. Bermejo and M. A. Muñoz-Fernandez, "Severe acute respiratory syndrome, a pathological immune response to the new coronavirus-implications for understanding of pathogenesis, therapy, design of vaccines, and epidemiology," Viral immunology, vol. 17, no. 4, pp. 535-544, 2004.

[156] H. Popper, "Clinical pathologic correlation in viral hepatitis. The effect of the virus on the liver," The American journal of pathology, vol. 81, no. 3, p. 609, 1975. 